Canadian Journal of Family and Youth, 12(2), 2020, pp. 60-68

\title{
The Effects of Immigration on Families
}

\author{
Kiarra Mostoway ${ }^{1}$
}

\begin{abstract}
This paper looks at the many different areas in which immigration can impact families, both separate and as a whole. It looks at the different institutions involved in perpetuating marginalization of foreigners, such as the workforce, education, and gender roles. I also incorporate some of my own insights of being the child of a Mexican immigrant.
\end{abstract}

\footnotetext{
${ }^{1}$ MacEwan University
} 


\section{Introduction}

Since the beginning of Canada's history, we have been a nation of immigrants built on diversity. Much research on immigrants focuses on Western, white, middle-class views and tries to apply these theories to all contexts, which simply does not work. Different cultures function based on different moral and value systems and the imposition of one on another is what leads to issues of racism, classism, and sexism. By taking an ethnocentric view, Western nations often forget that "immigrant families enter a country profoundly structured by race, and this racialized structure shapes their identities, social contexts, opportunities, and family interactions" (Hardie, Seltzer, 2016, p. 322). Furthermore, this stratification leads to discrimination in schools, the labour market, and housing which contributes to increasing social and economic inequality. These structural constraints only serve to perpetuate themselves and reinforce a negative 'us' versus 'them' discourse. Using my mother, a Mexican immigrant, as inspiration, this paper looks at the different ways that families can migrate and be affected by that migration, both as individuals and as a whole, taking specific interest in Mexico and the Spanish culture. I look at how immigration affects mothers, father, and children, as well as the effects on education, health, and the influence of gender roles and the experience of dissonance between cultures. I also incorporate my own personal experience of being the child of an immigrant. With immigrants making up over $20 \%$ of the Canadian population as of 2016 and only growing (Statistics Canada, 2016), I hope to bring light to the issues faced by immigrants and their families in order to challenge the dichotomous ideology that is present in modern discourse.

\section{Navigating Culture/Independence /Support}

Over the last few decades, arguably even the last half century, society has been moving away from the idea of family as a unit made up of a white mother, father, and two children. Nonstandard families are becoming more typical, therefore it doesn't necessarily make sense that we continue to make our judgements based on a nuclear family ideal. Despite this, many people still immigrate in hopes of finding a better life; in other words, in hopes of living the American Dream. Since the late 20th century, the family has shifted in many ways. Now with longer life expectancies there is a prolonged period of childhood, an infantilization of adult children and therefore an elongation of the transition to adulthood, extended schooling, delayed marriage, divorce, having children out of wedlock, and the list goes on (Hardie and Seltzer, 2016). With all of this variety in the types of 'families' today, those who immigrate to Western societies still have a difficult time finding where they fit in. It is incredibly difficult to move up in a society where you have no connections. Mexicans tend to live in a collectivist type of society built on connections and interactions with other people, whereas the the majority of Western cultures tend to be very individualistic and 'pull-yourself-up-by-the-bootstraps' (Vesely et al. 2019). Those who are born and raised in one place have what is called social capital: "at its core social capital is associated with the ways in which individuals connect with one another to create networks that allow for efficient flow of information that benefits those within the relationship network" (Tang, 2015, p. 24). Because of immigrant exclusion from mainstream society, ethnic enclaves emerged as a way for those who hold similar values and cultural beliefs to congregate and reproduce themselves. 
Generally speaking, immigrants have been shown to exhibit cultural traits and values that differ from those of dominant Western culture, such as "speaking Spanish at home and reporting Catholicism as their religion" (Tang, 2015; Guendelman, 2018, p. 1121). Mexican culture, where many immigrants to the United States and Canada are from, touts traditional gender roles and elder respect, or what they call machismo, respeto, and familism. Respeto refers to the idea of respect "based on hierarchical differences related to age, gender, and social class", machismo (and the feminine marianismo) "encourage self-sacrifice among women and empower men in the family hierarchy" (Vesely et al., 2019, p. 714) and familism "encourages feelings of loyalty, reciprocity, and solidarity within families and emphasizes the importance of maintenance of family ties" (Vesely et al., 2019, p. 712). These form the base values that Mexican culture is built on. Upon immigration, many Hispanic families have great difficulty accepting the fend-for-yourself attitude present and in turn "have had negative experiences with service providers who are discriminatory or culturally insensitive, a widely reported problem that leads to cultural distress, underutilization of services, and lack of treatment compliance" (Vesely, et al., 2019, p. 734) which only serves to perpetuate their marginalization from society, which leads to further economic risk, and then less opportunity for future generations, and so the cycle continues (Guendelman, 2018).

\section{Youth Experience}

Children and adolescents experience the transition of immigration much differently than their parents do. Similarly, to their parents, youth will face issues such as poverty, linguistic isolation, and discrimination from their peers and the institutions they interact with (Guendelman et al., 2018). In contrast to other youth raised in the Western individualistic world, immigrant youth have been noted to have and maintain close familial ties in both by choice and because they feel they have a sense of obligation to their families due to their cultural upbringing (Hardie and Seltzer, 2016). While immigrant children are more likely than non-immigrant children to adhere to cultural norms and practices, this trend has been found to fade out by the second generation (Hardie and Seltzer, 2016). Despite this, Ayon (2018) has found that "cultural socialization is associated with future levels of ethnic identity exploration, resolution, and affirmation" so perhaps not all hope is lost if youth are introduced to their culture thoroughly (p. 223).

An area where immigrant youth suffer more is through support. "Parents' support for their children during the transition to adulthood has been called a hidden source of inequality because the value of resources parents transmit is conditional on parents' financial, human, and social capital" (Hardie and Seltzer, 2016, p. 322), which are all areas in which non-immigrant families will immediately have an advantage, whereas immigrant families lack the history and connections to help their children in the same way. Because of this, when comparing with their peers, many immigrant children may be reluctant to turn to their parents for advice because they feel they do not fully understand the society that they've adopted. They may also fear creating conflict with their parents over their differing cultural values (Hardie and Seltzer, 2016). Regardless of cultural conflict, youth perceiving support from their parents can be just as beneficial as physical support. Young people take perceived support as a 'safety net' that may propel them 'to take calculated risks, like pursuing graduate education or starting a business. Perceived support is associated with 
economic well-being, particularly among low-income populations" (Hardie and Seltzer, 2016, p. 323). With these differences, it is easy to see how the communal attitudes of many first generation immigrant families can conflict with their children acculturated with American individualism.

While these individuals try to maintain their identity, many also claim that in many ways they felt they were forced into reshaping and adopting new beliefs in order to feel as though they belonged to their new world. Many parents feel as though they lack agency in many of their decisions, as this new society has already has already deemed who they should be and how they should perform their roles (as mothers, workers, students, etc.) (Vesely et al., 2019). They found there was tension due to the fact that they were not empowered to make autonomous decisions is a racialized, marginalized, ethnic minority in a society that still "harbour[s] anti-immigrant beliefs" (Vesely et al., 2019, p. 715). Finding a balance between wanting their children to fit in and become a part of the culture more than they could be themselves, parents struggled with "maintaining traditions and instilling cultural identity related to familism and collectivism" while "also hop[ing]to instill American ideas of egalitarian gender roles and personal autonomy." (Vesely et al., 2019, p. 725). While not at the same level as described in these studies, I also experienced much of the culture clash that is described. By the time I was born, my mother had already been in Canada for about fifteen years, so she was fairly well acclimated to society but she stills struggled with getting my brother and myself to understand and appreciate where she came from. She was around 20 years old when she moved here as well, so she went through much of the transition to adulthood away from her home country which made the transition less strenuous (M. Mostoway, personal communication).

\section{Body Image}

Another lesser known area of Western influence is the cultural imperative for thinness in Mexico. This is one of the areas where the United States has heavily influenced pop culture, not only in Mexico but across the world. As is noted in the Romo and Mireles-Rios study (2016), as parents are the first and main agent of socialization in children's lives, tend to be the ones responsible for reinforcing the unrealistic female beauty standards that heavily emphasize thinness, and therefore by extension young girls' discontent with their physical appearances and self esteem (p.18). The authors claim that "girls who were weight- dissatisfied received more criticism from their mothers about their body sizes" and that "mothers who expressed that they themselves were weight-dissatisfied gave fewer compliments to their daughters, fewer body esteem- enhancing messages, and made more critical comments about their daughters' body sizes and shapes" (2016, p. 27). I have experienced much of this criticism in my own life, and only after growing up and moving out on my own did I realize how much social influence was involved in this behaviour as opposed to it simply being a personal choice.

In Mexico, there is a very clear distinction between the upper and lower classes, and to be a part of the upper class there are very rigid norms, including being and maintaining physical attractiveness. Although class distinctions are less prevalent in Canada, this is an idea that my mother brought along with her when she immigrated some 30 years ago and (albeit unconsciously)

tried to instill in her children. In Canada, weight is much more of a closeted topic, but in other places it is much more open for discussion. This is in part due to the fact that there is a culture in 
other countries around 'teasing' as a way to gently bring up sensitive topics. According to Romo and Mireles-Rios, "teasing has been controversial in Western society because European American parents view teasing as a threat to their children's positive developing self. However, in Latino culture, teasing about physical characteristics may convey playful and affectionate intent, such as an uncle using irony to tease his young niece that she is unattractive when in fact he knows she is pretty" (2016, p.19). When mothers immigrate, they come into new contexts with their previous understandings and therefore when it comes to teasing, they expect that their children will interpret it in the same way that they do (2016, p. 21). While it is not easy to challenge our upbringing and our socialization, it is possible to change our understandings of society. In terms of body satisfaction and beauty standards, the most effective way to reshape our thought is through exposure and time.

\section{Temporary Foreign Workers}

Temporary foreign work is one of the most common reasons for immigration to another country. In many cases, people will leave their home country with the intention of temporarily moving to make a better wage to provide for family back home, with the plan of eventually returning. While this seems reasonable in theory, this process is often extremely difficult and degrading in practice. In this type of work, workers are often exploited due to "employers' needs for low-wage, flexible labour that is available for irregular work schedules" (McLaughlin et al, 2017, p. 683) and therefore are made "to work long hours, sometimes 18 hours a day, for minimum wages, often under harsh, dangerous working conditions" (McLaughlin et al, 2017, p. 685) worse than those the Canadian citizens would bear. Given these circumstances, it can be argued that temporary foreign work is a form of modern indentured servitude due to the fact that these individuals come intentionally, but perhaps without fully understanding what they are getting themselves into or under false pretenses. Many immigrants feel indebted to their families' needs and are unaware of their rights due to language barriers which fosters abuse by employers, what McLaughlin et al. call 'total institutions' that "foster a climate of fear that prevents workers from accessing rights to which they are formally entitled" (2017, p. 686). For example, these individuals have "“tied" work permits [that] restrict workers to one specific job for one employer at one location, for a specified time period, effectively indenturing them" (2017, p. 686). Furthermore, "employers have the power to "name" those they choose to return and to fire those they find undesirable, which generally leads to their immediate forced repatriation, with no right to independent appeal" (2017, p. 686). Vesely et al. (2019) also notes that although workers are often grateful for their new opportunities, they also felt "constrained in terms of freedom and their choices" (p. 723) due to fear of deportation or judgement from a new society. All of these factors come together to create a climate that promotes racist and exploitative ideals towards visible minorities.

When most people think about temporary foreign workers, the image of a women taking care of another family's children as live-in caregivers often comes to mind. Despite this, many of the immigrants who work in the United States and Canada are more often than not men who work in agriculture. This group becomes categorized as "“permanently temporary," [as they are] unable 
to ever gain citizenship status or family reunification in Canada despite years and sometimes decades of employment here" (McLaughlin et al, 2017, p. 684). One such program that many of them come to work in is the Seasonal Agricultural Worker program, or the SAWP (McLaughlin et al., 2017). This is a government-run program in which individuals are brought into Canada for varying periods of up to 8 months to work in rural communities (2017, p. 685). Despite being government run, "According to Ontario and British Columbia surveys, over half of SAWP workers received no health and safety training or information. Many others experienced language and literacy barriers to understanding the information provided. One fifth lacked health cards. About half worked while they were injured or sick to avoid losing pay or due to fear of upsetting employers. Most did not know how to make health insurance claims or workers' compensation claims" (201, p. 687). Workers are put into inadequate and precarious environments that are not up to standard and are told that they should appreciate it simply because it is better, either treatment-wise or financially, than what they would receive back home. Furthermore, while in Canada these individuals are often segregated due to location, lack of transportation, and language barriers that leave them isolated and without a support system. The stress of the transition can often lead to martial issues, child discipline problems, and emotional alienation between children and fathers (2017, p. 689). Unable to socialize and form bonds, many immigrant workers end up developing mental health issues, such as anxiety and depression, which can become exacerbated upon returning home to find that their children don't remember them, or only view their relationship a commodity due to the exchange of gifts that usually occurs (2017, p. 691). Children may often end up feeling abandoned by their parents, which in turn can lead to them having their own emotional and behavioural problems, such as rebelling against mothers and teachers, increased physical and mental illness, and premature pregnancy (2017, p. 693).

The parent who stays behind has to adapt to new circumstances as well. They have to take on more responsibility in every area of daily life, and the stress of having to be the sole caregiver, as well as possible jealousy and distrust can lead to the break-up of marriages (2017, p. 695). This transition can cause serious harm to the functioning of the family that can further cause difficulties among successive generations that will serve to undermine familial cohesion (2017, p. 695). Overall, it is difficult to weigh the pros on cons of these situations. On the one hand, immigrants need to support themselves and their families; on the other, they are being exploited for their labour and made to work in despicable conditions. This is what McLaughlin et al. refer to as the "contradictory dual sacrifice: a sacrifice for their families and a sacrifice by their families." (2017, p. 690). While my parents have never been temporary foreign workers, my father did work shiftwork in the oilfield, so he was gone a majority of the time when I was growing up. I can relate to many of the same things that other children would have experienced; to some degree there was always a detachment between my father and I simply due to the fact that he was not around enough for us to develop a deep bond. I resented that for much of my childhood, and it took me a long time to realize the sacrifices that were being made for the betterment of our family.

\section{Education}

Regardless of immigration status, it has been found that family involvement in education is shown to benefit and increase academic outcomes (Tang, 2015). When families immigrate, 
however, they have a tendency to not engage in their child's education. This is due to many factors, but most namely the language barrier that prevents parents from effectively communication with teachers (Tang, 2015). Because of this, most immigrant parents emphasize the importance of learning English and other literacy skills as a priority because in their own lives it was the largest barrier to moving up and navigating social institutions (Tang, 2015; Vesely, 2019).

Parents also have difficulties in acclimating to the advanced educational culture in the United States. It is very common for parents to put their children's names on waiting lists for good schools before they are born, and to encourage them to start reading and writing by the age of three or four. In most other parts of the world, including Mexico, this is not the norm and comes as quite a shock upon moving. According to Guendelman et al. (2018), this is because "immigrant parents viewed reading as part of a child's formal education, and did not engage in early reading with their children because they expected their child to learn literacy skills once they entered school" (p. 1124). In Mexico, parents are only responsible for the moral development of their children while the school is responsible for the educational development, therefore parents tend to refrain from participating in their child's academic life as it is seen as infringing on the teacher's expertise (Tang, 2015). In contrast, Canadian/American cultures expect that parents work with the school and the child to provide the best outcomes. Upon adjusting to the new system, most families do begin to engage when they feel they are welcome and invited to, such as at parent-teacher conferences (Tang, 2015). Looking at the environment of North American schools, it is not hard to understand why immigrant families would find it intimidating and difficult to navigate. Despite this, parents do still have positive attitudes towards education and educational attainment and want their children to succeed (Tang, 2015).

\section{Gender Roles}

When families immigrate, it may be easier for women than for men to adjust to the new North American culture when it comes to parenting. Mexico generally still holds onto rigid gender roles when it comes to parenting, so for fathers it may be a bigger shock to find out that more is expected of them upon moving. Traditionally, men are thought to be the provider of the family, and therefore migration has begun to be incorporated as part of being a good husband, in spite of all the negative consequences that come from not only the separation of the family, but the reinforcement of such destructive gender roles (McLaughlin et al., 2017). Moreover, because of these strict norms, McLaughlin et al. (2017) found that the daughters of temporary foreign worker fathers become vulnerable to abuse and violence at the hands of other men in their communities because they are seen 'exposed' without the presence of a male in the home. Fathers who had immigrated to the United States were found to be less engaged, specifically with younger children, when it came to activities such as eating with, reading to, and other physical warmth and caregiving (Guendelman et al., 2018). This is concerning when findings from other studies posit that: "Involved fathering of young children is associated with fewer cognitive delays, better academic performance, fewer behavioral problems, and stronger social-emotional skills such as sustained attention and emotional regulation during childhood and beyond." (Guendelman, 2018, p. 1118). 
While immigrant fathers may not readily adopt North American childrearing duties, immigrant mothers also have to make an adjustment to their new culture. A new trend for mothers to adapt to is the 'intensive mothering' that takes place in many Western households. According to Vesely et al. (2019), "Intensive mothering ideology reflects ideas that child rearing should be "child-centered, expert-guided, emotionally absorbing, labor-intensive, and financially expensive" and that this rearing should be carried out by the mother as the child's "central caregiver" (p. 715). In other words, mothers need to have all-hands-on-deck in every aspect of their child's life in order to ensure they attain the best social and psychological outcomes possible. By North American culture enforcing this as the best and only appropriate way to parent, it effectively marginalizes every other culture that doesn't subscribe to the same ideals. Mexican mothers become vilified for their collectivist, it-takes-a-village approach to parenting, as this perspective paints these women as deficient and "ignore[s] immigrant mothers' strengths and unique ways of adjusting and persisting despite difficult circumstances" (Vesely et al., 2019, p. 712). Perspectives such as these fail to recognize the "social made' challenges created by immigration laws and policies that structure (and limit) their opportunities and can stymie family adaptation and well-being" (Vesely et al., 2019, p. 712), as well as the fact that many families do try to incorporate new parenting styles into their lives by getting advice from family back home and from local institutions in an effort to assimilate (Vesely et al., 2019). In spite of the perceived differences in parenting styles, many Latino parents parent by authoritative styles (high control but also high warmth), which is also true of most American and Canadian households (Ayon, 2018). In the end, all parents want what is best for their children, the only difference is how they go about achieving their goals.

\section{Conclusion}

Immigration has the ability to affect many different people and many different areas of social life. It affects the family as a whole differently than it does its' individual parts. It affects social connection, educational attainment, body image, the workforce, and social structures such as gender and class. Immigration contributes greatly to the global economy, not just fiscally, but educationally and socially as well by breaking down the barriers that separate us. As the world continues to become more racially/ethnically diverse, it is important to study and understand the separation that we are continuing to uphold between 'us' and 'them', and why we are maintaining it. If globalization can teach us anything, it is that you cannot demand a service while simultaneously degrading those who provide it for you. I am thankful for the upbringing I received, I have had the opportunity to experience many more things than so many people my age and I can never thank my parents enough for that. Hopefully with further education, the societal shifts that come with increased diversity will lead to a place of more understanding and acceptance of difference. 


\section{References}

Ayon, C. (2018). Latino Immigrant Family Socialization Scale: Development and Validation of a Multidimensional Ethnic-Racial Socialization Measurement. Social Work, 63(3), 222-233.

Guendelman, S., Nussbaum, J., \& Lahiff, M. (2018). Hispanic Immigrant Father Involvement with Young Children in the United States: A Comparison with US-Born Hispanic and White non-Hispanic Fathers. Maternal \& Child Health Journal, 22(8), 1118-1126.

Hardie, J. H., \& Seltzer, J. A. (2016). Parent-Child Relationships at the Transition to Adulthood: A Comparison of Black, Hispanic, and White Immigrant and Native-Born Youth. ParentChild Relationships by Nativity and Race/Ethnicity, 95(1), 321-353.

McLaughlin, J., Wells, D., Mendiburo, A. D., Lyn, A., \& Vasilevska, B. (2017). 'Temporary Workers', Temporary Fathers: Transnational Family Impacts of Canada's Seasonal Agricultural Worker Program. Industrial Relations, 72(4), 682-709.

Mostoway, M. (November 5). Personal Communication.

Romo, L. F., \& Mireles-Rios, R. (2016). Latina Immigrant Mother-Daughter Communication About Their Body Self-Esteem and Weight Dissatisfaction: An Exploratory VideoObservational Study. Journal of Latinx Psychology, 4(1), 18-31.

Statistics Canada. (2019). Immigration and ethnocultural diversity: Key results from the 2016 Census. Retrieved from https://www150.statcan.gc.ca/n1/dailyquotidien/171025/dq171025b-eng.htm?indid=14428-1\&indgeo=0

Tang, S. (2015). Social Capital and Determinants of Immigrant Family Educational Involvement. Journal of Educational Research, 108(1), 22-34.

Vesely, C. K., Letiecq, B. L., \& Goodman, R. D. (2019). Parenting Across Two Worlds: LowIncome Latina Immigrants' Adaptation to Motherhood in the United States. Journal of Family Issues, 40(6), 711-738. 